\title{
A Systematic Approach to the Management of a Construction Complex under the Conditions of Digitalization
}

\author{
Ekaterina Tereshko1 ${ }^{*}$, Irina Rudskaya ${ }^{1}$ \\ ${ }^{1}$ Peter the Great Saint Petersburg Polytechnic University, St. Petersburg, Polytechnicheskaya, 29, 194064, \\ Russia
}

\begin{abstract}
The study of industry digitalization in Russia is relevant and promising in accordance with global trends and the main strategic documents of the Russian Federation in the context of increasing productivity, reducing costs, and increasing efficiency. The purpose of this study is to describe a systematic approach to managing a construction complex under the conditions of the digitalization of the economy from the micro level (the level of organizations) to the level of municipalities and regions. The article describes the process of transition to digitalization at the micro level in a construction complex and also analyzes the options for digitizing investment and construction projects at the micro level. It also describes the structural integration of a construction complex from the micro level to the level of the municipality/region through information services and through formed proposals for the formation of a management system for such construction complexes in municipalities and regions of Russia under the conditions of the digitalization of the economy. Based on the conducted analysis and the formed proposals, problems regarding the management of a construction complex of a municipality/region under the conditions of the digital economy are identified, namely: (1) a lack of developed standards for regulating the digital modeling of buildings; (2) a low level of employee ownership of software complexes that form building information modeling at the micro level; (3) the need for the continuous professional development of employees; and (4) the poor integration of some software products. In the future, based on the results of this study, it will be possible to form the structure of an information system for managing urban development and the space of municipalities, as well as a strategic approach to managing these digital processes at the municipal and regional levels in the regions of Russia.
\end{abstract}

Keywords: Construction complex; Construction industry; Digitalization; Regional and urban development; System approach

\section{Introduction}

Currently, the process of digital transformation is taking place, and digital and robotic processes that contribute to the optimization of routine processes are being actively introduced into industries and complexes. Considering industry adaptation to the processes of digitalization, we can distinguish such industries as those of agriculture, oil and gas, healthcare, construction, energy, etc. (Dmitrievsky et al., 2016; Leonov, 2018; Gorbunova et al., 2019; Mozokhin and Shvedenko, 2019; Tereshko and Rudskaya, 2020).

The construction industry is a promising and rapidly developing industry in the context of the implementation of digital processes at the micro level. It is in this industry that

*Corresponding author's email: ektereshko@mail.ru doi: 10.14716/ijtech.v12i7.5356 
innovative processes and advanced digital technologies are actively used, and the main design processes of production, non-production, and linear objects are gradually digitized and robotized (Oparina et al., 2018; Tereshko and Rudskaya, 2020; Tereshko et al., 2021). It is also possible to note the use of digital processes in the direct construction of capital construction projects.

Thanks to the approach of digital evolution in the construction industry, digital technologies provide the necessary development model and an improved organizational shift in an industry that is at the stage of implementing automation, artificial intelligence, machine learning, and innovation. The joint use of new technologies allows one to speed up decision-making, simplify the workflow, and avoid repeating tasks and mistakes. This fact is confirmed by scientific studies conducted by Russian and foreign authors (Sharmanov et al., 2015; Talapov, 2015; Grakhov et al., 2015; Kupriyanovsky et al., 2016; Sinyagov et al., 2017; Dronov et al., 2017; Razov et al., 2018; Doan et al., 2018; Chai et al., 2019; Jin et al., 2019; Oraee et al., 2019; Heigermoser et al., 2019; Chen and Lu, 2019; Santos et al., 2019; Chan et al., 2019; Asadi et al., 2019; Hong et al., 2019; Al-Saeed et al., 2020).

Scientists have considered different aspects of digital processes of construction production and technologies of building information modeling (BIM). For example, the authors in Jin et al. (2019) and Santos et al. (2019) examined the importance of the development of BIM technologies through studying publication activity in scientometric databases, as well as the impact of these studies on the sustainable development of territories. In other works (Talapov, 2015; Sinyagov et al., 2017; Chen and Lu, 2019; Asadi et al., 2019; Al-Saeed et al., 2020), various aspects of managing digital processes, information flows in design, and construction are considered. Al-Saeed et al. (2020) addressed the concept of implementing digital objects (BDO) of BIM for automating the processes of manufacturers of construction products and expanding lean manufacturing. The structure developed by the authors in Al-Saeed et al. (2020) illustrates the advantages of BDO by reducing the number of production processes to effectively eliminate early errors in the model, generate financial savings, and reduce material losses.

Some studies (Talapov, 2015; Grakhov et al., 2015; Razov et al., 2018; Heigermoser et al., 2019; Hong et al., 2019; Chan et al., 2019) are devoted to the prospect of the development of BIM technologies and the importance of implementing these technologies in construction organizations. For example, in the works by Grakhov et al. (2015) and Hong et al. (2019), the authors examined the opportunities that arise when using BIM technology, as well as problems that can be solved with it. In addition, Grakhov et al. (2015) analyzed the possible impact of the use of BIM technology on the economy of the industry and found that it contributes significantly to increasing the competitiveness of construction enterprises.

Of course, when moving toward a new format of organizing the activities of design and construction enterprises, there are a number of difficulties and barriers that may arise. This aspect is considered by the authors of several works (Sharmanov et al., 2015; Grakhov et al., 2015; Dronov et al., 2017; Razov et al., 2018; Oraee et al., 2019; Chan et al., 2019).

Research focused on the development of digital processes of investment and construction projects and complexes is also important (Chen et al., 2011; Shcherbina, 2017; Selyutina, 2018; Davydov et al., 2018; Churbanov et al., 2018). A qualitative assessment of the investment component is important to take into account at the time of obtaining a construction permit. Thus, this aspect is widely studied by researchers, and options for digital optimization are offered.

The scientific research analysis has shown that digital processes of construction production have been studied substantially, including various aspects of the development 
of BIM and the digital optimization of the construction process; however, the research did not find an approach focused on the digitalization of investment and construction projects at the municipal level in order to optimize urban development and form an effective construction complex for the municipality, contributing to its long-term development and providing a synergetic effect in the "municipality-construction organization-municipality" relationship. There are also no studies aimed at creating a unique digital environment for regulating the process of implementing projects at the municipal level.

The digitalization of investment and construction projects can contribute to the implementation of important tasks, both at the level of concluding transactions between an organization and an investor (an individual) and obtaining investment support for the construction of an object, and at the municipal level, when it is necessary to provide developers with investment support from the funds of the municipality. The digital model of the building, with the proper organization of project activities, allows for a comprehensive assessment of the capital construction object at the level of the tenders held. This study is conducted by the municipalities. Therefore, the study of the issue of the possible digitization of investment and construction projects is promising, and in the future, at the municipal level, it could become the basis for creating a single tool for regulating the activities of design and construction organizations, as well as the planned development of the territories of municipalities with a preliminary assessment of the requested places for the construction of objects. In this way, the construction industry can act as a driver of digital regional development, which it is advisable to consider through the prism of a regional construction complex (the organization of the activities of construction enterprises from project documentation to the commissioning of facilities, which is aimed at the integrated strategic development of the territory (Tereshko and Rudskaya, 2020; Tereshko et al., 2021).

The purpose of the study is to offer an information system for managing such construction complexes in the regions of Russia. In accordance with this goal, it is necessary to perform the following tasks: (1) describe the process of transition to digitalization at the micro level in a construction complex; (2) analyze the methodology of the digitization of investment and construction projects at the micro level; (3) describe the structural integration of a construction complex from the micro level to the level of the municipality/region through information services; and (4) identify problems in the management of a construction complex of a municipality/region in the digital economy.

\section{Methods}

The methodological basis of the study was the analysis and synthesis of the fundamentals of the functioning of construction enterprises and organizations in the digital environment using BIM technologies in the context of the territories of the Russian Federation. The study uses qualitative research methods, which consist of a meaningful subdivision, generalization, comparison, and interpretation of text. It uses the symbiosis of some approaches, namely the interpretive approach (Patton, 1980), the network approach (Bliss et al., 1979), the quasi-statistical approach (Miles and Huberman, 1994), nonnarrative analysis (Mishler, 1986), etc. The use of these approaches allowed us to categorize data and establish links between categories, which formed the basis for writing this article when forming a systematic approach to the management of a construction complex under the conditions of the digitalization of the economy. The qualitative methods are the basis for: (1) describing the stages of the transition of organizations and enterprises to BIM technologies; (2) analyzing options for digitizing investment and construction projects at the micro level; (3) describing the structural integration of a construction complex from the 
micro level to the level of the municipality/region through information services; and (4) identifying problems regarding the management of a construction complex of a municipality/region in the digital economy.

\section{Results and Discussion}

\subsection{Implementation of BIM Technologies at the Micro Level}

The transition to BIM technologies at the micro level is quite time-consuming and requires large capital expenditures as well as a long period of time. Considering the introduction of BIM technologies at the level of construction organizations, it is necessary to provide an integrated, systematic approach based on a clear separation of the stages of modeling and a financial assessment of capital construction projects. The approach involves dividing the areas of responsibility between the structural divisions of a construction organization. Considering that the main stages of creating a BIM model of an object are a detailed project (DP) model and models at the stages of project documentation (PD), working documentation (WD), and executive documentation (ED), it is necessary to allocate the stage of creating a DP model to the functional area of responsibility of a separate division of the organization, which will allow for the high-quality validation of the initial model for the subsequent stages of building PD and WD models (Talapov, 2015). Important when implementing BIM is the allocation of structural units, such as the standardization department and the BIM department, which should be responsible for the basic design elements that form the basis for modeling capital construction projects within the organization in the form of standard prefabricated structures. A standardization department is also necessary due to the lack of BIM standards at the state level with regard to the territory of the Russian Federation; therefore, this department should be responsible for the formation and constant updating of the organization's internal standards for BIM in accordance with current solutions (Selyutina, 2018).

For the implementation of BIM technologies in design organizations and in structural design divisions of construction organizations whose activities are focused on modeling PD and RD and also on the quasi-statistical approach (Miles and Huberman, 1994) and narrative analysis (Mishler, 1986), the following stages can be proposed:

Stage 1. Survey of the organization. The analysis of business processes is carried out at the first level. It is necessary to provide an analysis of the design organization (the department engaged in design in a construction organization) to build a general structure of the activity at that moment in time.

Stage 2. Development of a plan and tactics for the application of pilot projects for the implementation of BIM. The analysis of business processes is carried out at the second level. On the basis of standard projects, it is necessary to ensure well-established work and adjust business processes. For this purpose, it is necessary to choose two or three pilot projects that will form the basis for the modernization of the organization's activities. Detailed automation process plans are developed for these pilot projects.

Stage 3. Coordination of the plan and tactics for the application of pilot projects for the implementation of BIM. Business analytics are conducted at the third level. The pilot project is selected. Based on this, it is necessary to ensure that the work plan is coordinated with the working group. The formation of tasks should be carried out in accordance with the plan of the first pilot project. Project work takes place in the normal mode.

Stage 4. Development of the following pilot projects. Similar to in stage 3 , the design process of other pilot projects is implemented.

Stage 5. Development and approval of a general plan for the implementation of BIM design in the organization. An analysis is conducted of business processes at the fourth level 
by comparing pilot projects, drawing diagrams of the business processes of the organization, and identifying bottlenecks in the design, including in terms of automation. Proposals are formulated to eliminate bottlenecks. Also, an important step at this stage is the evaluation of the existing software and all the plugins and add-ons developed for it. The development and approval of the development plan of the project organization (the department engaged in design) takes place within the automation of key design subprocesses.

Stage 6. Implementation of the BIM implementation plan. Recommendations are considered based on the results of the analysis of the organization's business processes, which are based on the pilot projects. The organization's software systems are replaced or modernized. Working groups are formed and assigned to projects. If necessary, training is provided for employees (especially in terms of the new software) who are part of the project working group. New staff units are recruited for the positions of BIM manager and BIM coordinator.

These stages will allow the project organization (division) to competently and efficiently develop its work further, which will ensure a gradual transition to the digital level of design and the organization of the highest quality of work. Note that it will not be possible to make a quick transition to a new work format since not all employees own the necessary software, and not all of them are able to quickly switch from one platform to another. Of course, the transition will also require significant material costs: (1) new software; (2) employee training; (3) consultations with specialists, and (4) the modernization and updating of existing software.

An important task in the design of any capital construction object is the accuracy of estimating the cost of the building planned for construction. It is of paramount importance to assess the amount of materials and resources required for construction, which will allow the formation of a summary statement of the scope of the work. Let us consider the specifics of estimating the amounts of materials and resources separately, as well as methods for optimizing data collection (Talapov, 2015; Churbanov et al., 2018; Chan et al., 2019).

I. Estimation of the amount of materials. When designing using BIM technologies, geometric models contain information about all the materials, only it is quite laborious to process them manually for each element. Therefore, with the correct settings regarding the source data (families), as well as specifications for the projected object, this process can be automated and robotized. An important condition for automation is the encryption of the elements of the designed building, which will allow the further identification and unloading of the necessary parameters by elements.

II. Estimation of the amount of resources. There are two main methods for calculating the estimated cost of a construction object: basic index and resource. To assess the required amount of resources according to the basic index method, regulatory frameworks are used, which are structured according to the types of construction and installation works and the hierarchy of the construction processes. Regulatory frameworks allow us to obtain information about the required amount of resources per unit volume of a particular building structure (Talapov, 2015). The regulatory bases contain the configurations of operations for specific construction processes and the compositions of working links, machines, mechanisms, and tools that are necessary for the construction of building structures, for which a single price is subsequently calculated.

The regulatory bases that exist today in the territory of the Russian Federation include territorial unit prices in construction, federal unit prices, and enlarged standards for the prices of structural solutions. The databases do not contain up-to-date data on individual prices since they are based on data from the state element estimated norms (SEEN). Thus, 
unit prices are usually formed from base prices that are relevant for a certain year - the base year. To switch from the basic price to the current one, it is necessary to use indexes that are updated annually. The indexes are different for different types of construction and installation works, and they may also depend on the administrative and territorial location of the object (its geographical location).

Let us consider the second main method of calculating the estimated cost resource. This method allows one to give a more accurate estimate than the basic index one, but it is also the most time-consuming in terms of calculation. Passing the examination when using this method will take longer because it is necessary to check all the prices for the resources used in the projected object.

It should be noted that the regulatory framework can be replaced by the internal prices of construction companies. This approach is another option when calculating the economic cost of the projected objects.

Therefore, BIM can help to implement the symbiosis of material and resource evaluation. To implement this task, it is necessary to do the following:

1) Carry out coding (encryption) and the naming of the structural elements that make up the digital model of the projected object. Coding will allow the comparison of structural elements with single prices from regulatory databases. The ideal option is to revise the regulatory bases of individual prices in order to adapt them to the digital modeling of buildings (i.e., the introduction of uniform standards at the state level), which will allow for the better design of capital construction projects with initially correctly specified codes (ciphers).

2) Form a single methodology for calculating the estimated cost at the state level, either based on the basic index method or on the resource method.

With the help of a digital double of the designed building, it will be possible to read the ciphers of the elements and carry out further comparison in the digital environment with the codes (ciphers) of prices, which will be updated on an annual basis. Most importantly, the introduced prices should be approved at the legislative level in a single symbiosis of BIM development in Russia. Also, depending on the Russian territory, the introduced prices can be regulated according to the principle of a "fair price," which will allow tenders to be conducted for the selection of contractors (if we consider a two-stage or more system of organizing construction production) based on a comparison of aggregated unit prices, as well as on checking the estimated cost.

It is especially important to introduce an algorithmized estimate of the cost of construction of capital construction projects using BIM for those objects that are planned to be built using public funds.

\subsection{Proposals for the Formation of a Management System for Construction Complexes in the} Regions of Russia in the Context of the Digitalization of the Economy

Interaction with construction organizations at the municipal and regional levels in the digital environment plays an important role in ensuring the development of urban space. It is through numbers that it is possible to exercise control during the implementation of large-scale infrastructure projects by optimizing and balancing the urban environment (Grakhov et al., 2015; Heigermoser et al., 2019). For this interaction, it is necessary to form and implement an information system for managing urban development and the space of municipalities, which should be synchronized with the projects of objects under construction, creating a digital analogue of the municipality/region. The information system will be able to provide the systematization of data on objects under construction, including energy consumption and resources, and within the framework of forming project 
budgets. The process of operating this system should be organized from the stage of holding tenders for the construction of a capital construction object by sending requests to construction organizations and enterprises. Next, it is necessary to validate projects at the municipal level with further support for optimal ones within the framework of urban environment development. This system will be able to generate requests for the development of projects in accordance with the developed urban space development plan, as well as allowing tenders to be conducted in a remote format with the granting of the right to build a particular construction organization based on the projects received in digital format. A key condition for construction organizations should be the provision of information on the planned object in a digital form by including with the application a digital federated model of the building (Figure 1).

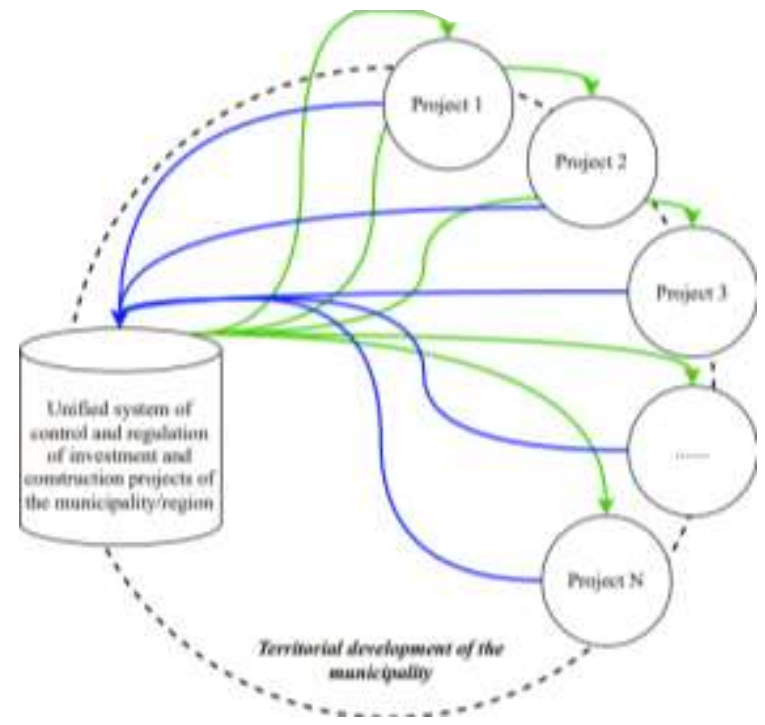

Figure 1 General structure of the regulation of investment and construction projects at the municipal level

For the transition to the digitalization of investment and construction projects at the municipal level, it is necessary to carry out the following steps:

1) Develop and implement a unified urban information system focused on the control and development of capital construction projects that form the urban space.

2) Develop federal standards that will ensure the encryption of elements of BIM models of capital construction projects.

3) Form a unified pricing system that will correlate with the new BIM design technology with an annually updated database. It is possible to introduce adjustments to prices according to the "fair price" rule for the regions of Russia, depending on their territorial features and current economic situations.

A more detailed model for integrating the digital transformation of an investment and construction project with the municipal and federal levels is shown in Figure 2. When forming a model of the integration of the digital transformation of an investment and construction project with the municipal and federal levels, an interpretive approach was used (Patton, 1980), which allowed, based on approaches to the implementation of the management of a construction complex (Talapov, 2015; Tereshko and Rudskaya, 2020, Tereshko et al., 2021) as well as on the possibilities regarding the development of BIM technologies (Talapov, 2015; Sinyagov et al., 2017; Chen and Lu, 2019; Asadi et al., 2019; Al-Saeed et al., 2020), the formation of a logically consistent model. This model reflects the step-by-step process of project development, the formation of project documentation at the 
stages of PD and WD, and the passage of expertise. The characteristic connections reflect the steps (i.e., the sequence that is necessary when implementing this algorithm). It should be noted that the black arrows reflect the first circle, and the blue ones reflect the second one after the approval of the project documentation, passing the examination, the issuing of a construction permit, and receiving appropriate funding from the municipality.

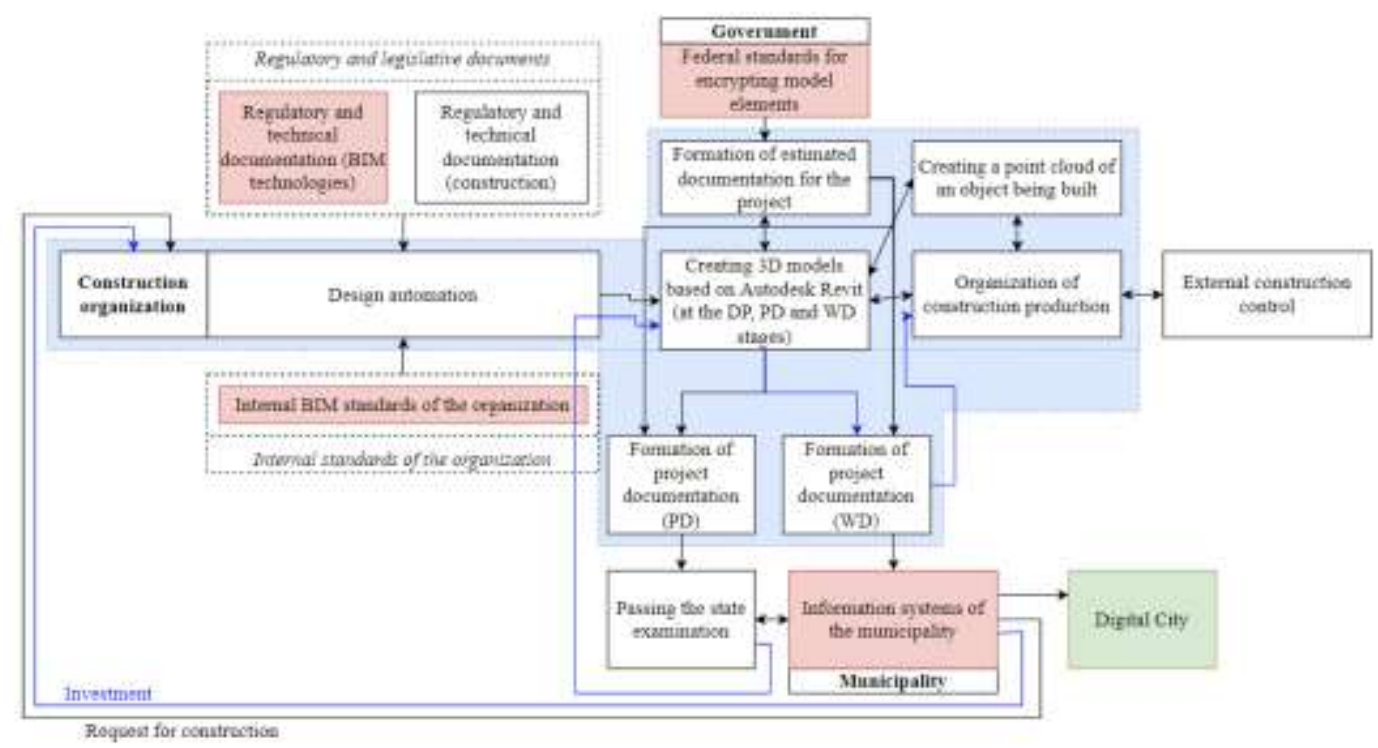

Figure 2 A model for integrating the digital transformation of an investment and construction project with the municipal and federal levels

According to Figure 2, the "municipality information system" issues a building request to construction organizations that, after processing the request, begin the computer-aided design process (see Figure 1). As part of this process, a 3D model or a "digital twin" of the future object is created; Revit software is recommended for this since it allows for the maximum coverage of design processes by forming a single model of the future object (BIM 360) using cloud services. Based on the digital twin of the construction object that is created, it is possible to ensure the formation of estimated documentation for the project, which will only be possible with the correct coding of the model elements (Brumana et al., 2018). The automatic unloading of the required documentation of the PD and RD stages is also possible. Consequently, the passage of state expertise of construction objects is significantly accelerated, and the model, together with the documentation, is reentered into the "information system of the municipality", the evaluation of all the received projects takes place, and some projects are supported by investments. The generated model can later be used on the construction site when organizing construction production, and by reading the elements of the building being erected with the help of a point cloud, it will be possible to monitor the quality of construction. When organizing such an approach, a visual and transparent system of the external control of construction is formed, and simulated objects with financial support can become the basis for the formation of a digital city.

Also, by 2024, it is planned to implement the federal project "Digital Construction," which will provide a digital platform for design. The digital construction system is supposed to speed up the production process of construction enterprises by $30 \%$ (URL: http://varjag.net/rossiya-k-2024-godu-zapustit-sistemu-cifrovoe-stroitelstvo).

When implementing an information system for managing urban development, including a construction complex, the following key problems can be identified: (1) the lack of developed standards for regulating digital building modeling; (2) the low level of employee ownership of software complexes that form BIM at the micro level; (3) the need 
for the continuous professional development of employees; and (4) the poor integration of some software products. The problems are mainly tied to the BIM standards and the organization of activities within construction enterprises and organizations; therefore, for the organization of an information system for urban development management, it is necessary to provide an integrated approach focused primarily on the micro level of this chain.

\section{Conclusions}

In this article, a systematic approach to the management of a construction complex under the conditions of digitalization was considered from the micro level (the level of construction organizations and enterprises) to the level of the municipality/region. The basics of the transition to the digital environment for construction enterprises in accordance with the six stages identified are defined, and the option of the digitalization of investment and construction projects is considered in detail. A model for integrating the digital transformation of an investment and construction project with the municipal and federal levels is proposed, and the main barriers to the implementation of this model are identified.

At this stage, the proposed system approach can be used as a basic structure for managing the information space of construction complexes at the municipal and regional levels. In addition, using the proposed approach, it is possible to organize the activities of a large number of stakeholders in accordance with the Strategy of Scientific and Technological Development of the Russian Federation.

In the future, Moscow, St. Petersburg, and the Moscow Region can organize such a regional information system in the territories of the Russian Federation, and 53 regions of Russia are potentially ready, based on the rating of the regions' readiness for the digitalization of construction complexes (Tereshko et al., 2021). In due course, based on the results of this study, it will be possible to form the structure of an information system for managing urban development and the space of municipalities, as well as a strategic approach to managing these digital processes at the municipal and regional levels in the regions of Russia.

\section{Acknowledgements}

The research is partially funded by the Ministry of Science and Higher Education of the Russian Federation under the strategic academic leadership program 'Priority 2030' (Agreement 075-15-2021-1333 dated 30.09.2021).

\section{References}

Al-Saeed, Y., Edwards, D.J., Scaysbrook, S., 2020. Automating Construction Manufacturing Procedures using BIM Digital Objects (BDOs). Construction Innovation, Volume 20(3), pp. 1471-1475

Asadi, K., Ramshankar, H., Noghabaei, M., Han, K., 2019. Real-Time Image Localization and Registration with BIM using Perspective Alignment for Indoor Monitoring of Construction. Journal of Computing in civil Engineering, Volume 33(5), http://dx.doi.org/10.1061/(ASCE)CP.1943-5487.0000847

Bliss, J., Ogborn, J., Grize, F., 1979. The Analysis of Qualitative Data. European Journal of Science Education, Volume 1(4), pp. 427-440

Brumana, R., Torre, S.D., Previtali, M., Barazzetti, L., Cantini, L., Oreni, D., Banfi, F., 2018. Generative HBIM Modelling to Embody Complexity (LOD, LOG, LOA, LOI): Surveying, 
Preservation, Site Intervention-The Basilica di Collemaggio (L'Aquila). Applied Geomatics, Volume 10(4), pp. 545-567

Chai, C., Mustafa, K., Kuppusamy, S., Yusof, A., Lim, C.S., Wai, S.H., 2019. BIM Integration in Augmented Reality Model. International Journal of Technology, Volume 10(7), pp. 1266-1275

Chan, D.W.M., Olawumi, T.O., Ho, A.M.L., 2019. Perceived Benefits of and Barriers to Building Information Modelling (BIM) Implementation in Construction: The Case of Hong Kong. Journal of Building Engineering, Volume 25, https://doi.org/10.1016/j.jobe.2019.100764

Chen, K., Lu, W., 2019. Bridging BIM And Building (BBB) for Information Management in Construction. Engineering, Construction and Architectural Management, Volume 26(7), pp. 1518-1532

Chen, Y., Feng, C., Wang, Y., Wu, H., 2011. Using BIM Model and Genetic Algorithms to Optimize The Crew Assignment for Construction Project Planning. International Journal of Technology, Volume 2(3), pp. 179-187

Churbanov, A.E., Shamara, Y.A., 2018. The Impact of Information Modeling Technology on the Development of the Investment and Construction Process. Vestnik MGSU, Volume 13(7), pp. 824-835

Davydov, N.S., Pridvizhkin, S.V., Belkevich, A.V., 2018. Introduction of BIM Technologies in Terms of Pricing Through the Use of Automation Systems for the Production of Estimate Documentation. In: BIM-modeling in Construction and Architecture Tasks, pp. 8-13

Dmitrievsky, A.N., Martynov, V.G., Abukova, L.A., Eremin, N., 2016. Digitalization and Intellectualization of Oil and Gas Fields. Automation and IT in the Oil and Gas Industry, Volume 24(2), p. 13

Doan, D.T., Ghaffarianhoseini, A., Naismith, N., Zhang, T., Tookey, J., Ghaffarianhoseini A., 2018. Examining the Relationship between Building Information Modelling (BIM) and Green Star. International Journal of Technology, Volume 9(7), pp. 1299-1307

Dronov, D.S., Kimetova, N.R., Tkachenkova, V.P., 2017. Problems of Implementing BIM Technologies in Russia. Synergy of Sciences, Volume 10, pp. 529-549

Gorbunova, O.S. Petryakova, S.V., Rodionova, S.V., Pilnikov L.N., 2019. Robotization of Greenhouse Complexes in the Field of Digitalization of the Agricultural Economy. Education and law, Volume 4, pp. 123-130

Grakhov, V.P., Mokhnachev, S.A., Ishtryakov, A.H., 2015. Development of BIM Design Systems as an Element of Competitiveness. Modern Problems of Science and Education, Volume 1(1), pp. 580-580

Heigermoser, D., de Soto, B.G., Abbott, E.L.S., Chua, D.K.H., 2019. BIM-Based Last Planner System Tool for Improving Construction Project Management. Automation in Construction, Volume 104, pp. 246-254

Hong, Y., Hammad, A.W.A., Sepasgozar, S., Akbarnezhad, A., 2019. BIM Adoption Model for Small and Medium Construction Organisations in Australia. Engineering, Construction and Architectural Management, Volume 26(2), pp. 154-183

Jin, R., Zou, Y., Gidado, K., Ashton, P., Painting, N., 2019. Scientometric Analysis of BIM-Based Research in Construction Engineering and Management. Engineering, Construction and Architectural Management, Volume 26(8), pp. 1750-1776

Kupriyanovsky, V.P., Sinyagov, S., Namiot, D., Bubnov, P., Kupriyanovsky, J., 2016. The New Five-Year Plan of BIM-Infrastructure and Smart Cities. International Journal of Open Information Technologies, Volume 4(8), pp. 20-35 
Leonov, S.A., 2018. Integration of Healthcare, Education and Information and Communication Technologies in the Framework of Digitalization of Domestic Medicine. Actual Problems of Economics and Management, Volume 3, pp. 35-39

Miles, M.B., Huberman, A.M., 1994. Qualitative Data Analysis: An Expanded Sourcebook. Sage Mishler, E.G., 1986. The Analysis of Interview-Narratives. In: T. R. Sarbin (Ed.), Narrative Psychology: The Storied Nature of Human Conduct (pp. 233-255). Praeger Publishers/Greenwood Publishing Group

Mozokhin, A.E., Shvedenko, V.N., 2019. Analysis of the Directions of Development of Digitalization of Domestic and Foreign Energy Systems. Scientific and Technical Bulletin of Information Technologies, Mechanics and Optics, Volume 19(4)

Oparina, L.A., Dudakov, A.D., Mokin, A.S., 2018. Modern Trends in the Organization of Construction Production: From the Past through the Present to the Future. In: ObjectSpatial Design of Unique Buildings and Structures, pp. 228-235

Oraee, M., Hosseini, M.R., Edwards, D.J., Li, H., Papadonikolaki, E., Cao, D., 2019. Collaboration Barriers in BIM-Based Construction Networks: A Conceptual Model. International Journal of Project Management, Volume 37(6), pp. 839-854

Patton, M.Q., 1980. Qualitative Research \& Evaluation Methods. Beverly Hills, CA: Sage Publications

Razov, I.O., Bereznev, A.V., Korkishko, O.A., 2018. Problems and Prospects of Implementing BIM Technologies in Construction and Design. In: BIM-Modeling in Construction and Architecture Tasks, pp. 27-31

Santos, R., Costa, A.A., Silvestre, J.D., Pyl, L., 2019. Informetric Analysis and Review of Literature on the Role of BIM in Sustainable Construction. Automation in Construction, Volume 103, pp. 221-234

Selyutina, L.G., 2018. Life Cycle Management of a Capital Construction Object based on Modern Information Modeling Technology (BIM). In: BIM-Modeling in Construction and Architecture Tasks, pp. 3-8

Sharmanov, V.V., Mamaev, A.E., Boleiko, A.S., Zolotova, J.S.., 2015. Difficulties of Phased Implementation of BIM. Construction of Unique Buildings and Structures, Volume 10, pp. 108-120

Shcherbina, G.F., 2017. Application oF Bim-Technology to Improve the Quality of Construction. In: Russian Economy-Innovative Character, pp. 297-309

Sinyagov, S.A., Kupriyanovsky, V., Kurenkov, P., Namiot, D., Stepanenko, A., Bubnov, P., Raspopov, V., Seleznev, S., Kupriyanovsky, J., 2017. Building and Engineering based on BIM Standards as a Basis for Infrastructure Transformations in the Digital Economy. International Journal of Open Information Technologies, Volume 5(5)

Talapov, V.V., 2015. BIM Technology: The Essence and Features of the Introduction of Information Modeling of Buildings. Moscow: DMK Press

Tereshko, E., Romanovich, M., Rudskaya, I., 2021. Readiness of Regions for Digitalization of the Construction Complex. Journal of Open Innovation Technology Market and Complexity, Volume 7(1), pp. 1-17

Tereshko, E.K., Rudskaya, I.A., 2020. Digital Potential of the Construction Complex: The Concept, Essence and Problems of Development. Scientific and Technical Bulletin of SPbPU. Economic sciences, Volume 13(3), pp. 27-40 